\title{
COMPETÊNCIAS EM INFORMAÇÃO EM BIBLIOTECA MULTINÍVEL DE REGIÃO INTERIORANA DO ESTADO DA PARAÍBA, PB, BRASIL
}

\author{
INFORMATION LITERACY IN A COUNTRYSIDE \\ MULTILEVEL LIBRARY OF STATE OF PARAÍBA, PB, \\ BRAZIL
}

Midnai Gomes Bezerraa

Lucas Almeida Serafimb

\begin{abstract}
RESUMO
Introdução: As competências em informação (information literacy) são assunto recorrente na literatura de Biblioteconomia e Ciência da Informação, seja em abordagens teóricas sobre o fenômeno informacional na contemporaneidade, seja em relatos empíricos acerca da busca e uso da informação em Unidades de Informação. Em âmbito de implementação, a promoção de competências em informação ocorre em ações educacionais formalizadas, institucionalizadas, as quais reforçam e ampliam a tradicional educação de usuários de bibliotecas. Esta realidade, todavia, ainda não caracteriza a maior parte do ambiente informacional brasileiro, principalmente o escolar e acadêmico - multinível, escrutinado nesta pesquisa. Objetivo: Analisa o cenário de práticas orientadas por competências em informação em biblioteca multinível brasileira. Metodologia: Realiza pesquisa participante, alicerçada por conjunto de métodos para a descrição de práticas de informação, a saber: tour guiado em ambientes de informação, entrevista semiestruturada, pesquisa visual, e método de interpretação de sentidos. Resultados: Constata - em mais uma realidade de biblioteca brasileira multinível e localizada interiorana do nordeste brasileiro - um longo caminho a ser seguido pela biblioteca sob estudo na busca de capacitação em competências em informação; carece-se de fomento das habilidades mais básicas sobre o uso da biblioteca. De modo a supri-las, propõe uma política formal de competências em informação, alicerçada inicialmente pela indicação de dois cursos. Conclusões: A realização desta pesquisa oportunizou o aprofundamento e sistematização do contexto biblioteconômico local e, consequentemente, a proposição de política de melhoramento por meio de treinamentos com base em situações-problemas reais decorrentes da vida escolar e acadêmica dos usuários, de modo a torná-los competentes em informação.

Descritores: Competência em Informação. Educação de Usuários. Biblioteca Multinível.

${ }^{a}$ Mestra em Biblioteconomia (UFCA), Bibliotecária da Universidade Estadual da Paraíba (UEPB).

E-mail: midnaygomes@gmail.com

b Professor do Curso de Biblioteconomia da UFCA e do Programa de Pós-Graduação em Biblioteconomia da UFCA. Doutor em Ciência da Informação pela Universidade Federal da Paraíba (UFPB). E-mail: lucas.almeida@ufca.edu.br
\end{abstract}


Biblioteca Acadêmica. Biblioteca Escolar.

\section{INTRODUÇÃO}

Este artigo resulta de pesquisa realizada no Programa de Pós-Graduação em Biblioteconomia (Mestrado Profissional), na Universidade Federal do Cariri, cujo objetivo geral foi analisar as práticas orientadas por competências em informação dos usuários do sistema de bibliotecas da Universidade Estadual da Paraíba, Campus IV, Catolé do Rocha - Paraíba. As competências em informação (information literacy) é assunto recorrente na literatura de Biblioteconomia e Ciência da Informação, seja em abordagens teóricas sobre o fenômeno informacional na contemporaneidade, seja em relatos empíricos sobre a busca e uso de informação nas Unidades de Informação de contextos formais e especializados.

Na contextura prática, as competências em informação são fomentadas com base em ações educacionais formalizadas, institucionalizadas, as quais assumem o compromisso de promover não apenas habilidades de busca de informação - já desenvolvidas ao longo dos tempos pelos bibliotecários na tradicional educação de usuários - mas capacitar no uso de informação, a ser utilizada de modo eficiente (análise crítica e produção de novo conhecimento) e ético. Esta realidade, todavia, ainda não caracteriza o ambiente informacional brasileiro - principalmente o escolar e acadêmico - multinível (ALMEIDA; FREIRE, 2018), escrutinado nesta pesquisa.

O cenário atual, ainda por ser desbravado por colaboradores do movimento internacional pelas competências em informação, é reflexo de problemáticas mais amplas do modo como as bibliotecas brasileiras são geridas. Diversos autores já asseveram que a criação e implementação da maior parte dos serviços de informação não são precedidas de ações devidamente planejadas; ocorrem sem o reconhecimento prévio do público a que eles irão servir, isto é, sem a realização de estudo (sistemático, aprofundado, contextualizado) de usuário. De acordo com:

a) Islam e Islam (2009, p. 129, tradução nossa), "A maior parte das 
bibliotecas dos países em desenvolvimento ainda [...] são governadas mediante os modos mais primitivos. Essas bibliotecas estão envolvidas apenas em promover assistência aos usuários para encontrar livros";

b) Rowley e Roberts (2008), "há um consenso que os profissionais de informação e biblioteca são relutantes a se tornarem líderes, não considerando isto seu domínio, mas preferem focar nos seus assuntos 'profissionais' de biblioteca";

c) Andrade (2004, p. 42), "[...] uma das maiores deficiências na administração de unidades de informações brasileiras é a carência de instrumentos gerenciais";

d) Almeida (2005), "Por não estar totalmente incorporado à rotina do bibliotecário, o planejamento, quando ocorre, é como atividade esporádica e não como atitude permanente";

[...] de fato, muitos bibliotecários, de diferentes tipos de bibliotecas, baseiam suas operações em 'suposições irreais', pois não tem um conhecimento perfeito dos seus usuários, de suas necessidades e de seu comportamento [...] em geral, os bibliotecários conhecem superficialmente os usuários e que os serviços de informação não são adequados à demanda real. [...] os usuários não tem conhecimento do acervo e de todos os serviços que a unidade de informação pode oferecer, ou não sabem como utilizá-los. Como consequência, a maioria das bibliotecas e serviços de documentação convencionais é subutilizada, caracterizando-se pela baixa demanda efetiva sobre grande parte dos recursos e serviços oferecidos. (ALMEIDA, 2005, p. 15).

e) Milanesi (1983) "São raros os casos de bibliotecas universitárias pensadas para funcionar como tal, constituindo-se, quase sempre, em improvisos que as administrações promovem para resolver problemas que vêm de longe".

Destacar a relevância e necessidade de conhecimento sobre os usuários, e de suas demandas por competências em informação, é, portanto, a mola mestra desta pesquisa, a qual - nascida em contexto biblioteconômico multinível educacional, bastante peculiar, que reproduz, por vezes, as problemáticas de gestão de informação já retratadas em outras realidades - também se compromete em apresentar como produto uma proposta de política educacional para o desenvolvimento de competências em informação, a ser devidamente 
aprovada e institucionalizada pela comunidade local.

\section{DA EDUCAÇÃO DE USUÁRIOS ÀS COMPETÊNCIAS EM INFORMAÇÃO}

O surgimento da expressão "competências em informação" (information literacy) ocorre em paralelo ao estabelecimento da sociedade que fundamenta suas ações - nas mais variadas situações da vida humana - em torno da informação. Origina-se nos Estados Unidos, na década de 1970, através de Paul Zurkowski (1974), bibliotecário, advogado e presidente da Information Industry Association (IIA), em um relatório que teve como título: The Information Service Environment Relationships and Priorities. Esse documento foi elaborado para a National Commission on Libraries and Infomation Science, com a intenção de estabelecer diretrizes para um programa nacional de acesso à Information Literacy (ZURKOWSKI, 1974).

A tradução para a língua portuguesa não é consensual e, do mesmo modo, a sua compreensão teórico-prática é variada: "Competências em informação", "Competência em informação", Competência Informacional", "Alfabetização Informacional", "Literacia Informacional", Alfabetização Digital" e "Letramento Informacional" são alguns exemplos. De modo a construir entendimentos, os pesquisadores esforçam-se por fundamentar as suas categorizações. Campello (2009), Campello e Abreu (2005) e Dudziak (2001), apontam que os vocábulos "letramento" e "alfabetização" - tradução mais fiel ao termo literacy - denotam a educação primária de ler e escrever; o mesmo não ocorreria a palavra "competência", utilizada para descrever um conceito de amplo sentido no qual a aprendizagem é vista como processo e não um fim em si mesmo.

A preferência por "competência", de fato, prevalece nas pesquisas em língua portuguesa, incluindo este estudo, bem como os promovidos pelas principais instituições bibliotecárias do país: em 09 de agosto de 2011 foi aprovada, durante o XXIV Congresso Brasileiro de Biblioteconomia e Documentação a "Declaração de Maceió sobre Competência em Informação", documento que promove a competência informacional no Brasil e que conta com 
o apoio do Instituto Brasileiro de Informação em Ciência e Tecnologia (IBICT), Universidade de Brasília (UNB) e Federação Brasileira de Associações de Bibliotecários e Cientistas da Informação (FEBAB). Sem maiores pretensões de estabelecimento de terminologia única, emprega-se neste estudo o vocábulo "competência" no plural, seguindo o entendimento de que:

No presente artigo, o uso do termo "competências em informação" segue, de certo modo, alguns estudos de língua portuguesa que preferem o termo "competências" à "alfabetização", na tradução do termo literacy (VIRKUS, 2003). Compreende-se que o termo "competências" seria mais apropriado para o entendimento habilidades informacionais específicas para além dos métodos de alfabetização tradicionais. Já a escolha por "competências em informação", e não "competências informacionais", outro termo bastante recorrente, fundamenta-se no fato de que embora sejam termos com significados similares, o qualificador do substantivo information é um outro substantivo, literacy, e não um adjetivo (informational). (SERAFIM, FREIRE, 2012, p. 157).

Corrobora-se com o pensamento de que a preferência por um ou outro termo não deve sobrepor a prioridade da pesquisa em competências em informação. Para Owusu-Ansah (2005, p. 367 apud SERAFIM; FREIRE, 2012, p. 159), o crescimento surpreendente da informação na sociedade, e consequentemente das competências em informação, transforma a interpretação da information literacy em uma "[...] diversidade de objetivos e falta de consenso suficiente sobre a forma concreta de sua execução, que, por vezes, obscurece o significado de um conceito suficientemente claro para ser entendido com um mínimo equívoco".

Substituir information literacy por information competency ou fluência em informação apenas muda o nome ou descritor atribuído ao conceito, sem transformar, ou melhor, esclarecer o fenômeno que o identifica. O debate continuado sobre definições apropriadas [...] não tem benefícios práticos. Tal atividade pode se tornar, todavia, uma perda de tempo e energia preciosos. Este tempo e energia poderiam ser mais significativamente gastos na busca para melhorar as capacidades dos estudantes, explorar o papel que a biblioteca pode ter neste processo, bem como em determinar a legitimidade e vontade da participação da biblioteca na educação dos estudantes competentes em informação (OWUSU-ANSAH, 2005, p. 373, apud SERAFIM, FREIRE, 2012, p. 159).

O benefício do movimento em prol das competências em informação visa, 
majoritariamente, melhoramento de práticas em sistemas de informação tradicionais (ambiente biblioteconômico, por exemplo), apesar de não ser restrito a eles. É com base nesses contextos que são criados os padrões internacionais vigentes de competências em informação - um conjunto sistematizado de diretrizes que ampliam a tradicional educação de usuários.

No The Seven Pillars of Information Literacy, da Society of College, National and University Libraries (2011), a pessoa competente em informação é aquela que sabe:

a) Identificar: habilidade para identificar uma necessidade pessoal de informação;

b) Observar: avalia o nível de conhecimento atual e identifica necessidades de novos conhecimentos;

c) Planejar: habilidade para construir estratégias para localizar informações;

d) Reunir: habilidade para localizar e acessar informação necessitada;

e) Avaliar: habilidade para comparar e avaliar informações obtidas de fontes diferentes, conscientes das questões de autoridade $e$ parcialidade das informações apresentadas;

f) Gerenciar: organiza profissionalmente e eticamente as informações;

g) Apresentar: aplica o conhecimento adquirido, apresentando resultados de pesquisa, sintetiza velhos e novos dados para criar conhecimentos, disseminando-os através de meios variados;

Mais do que habilidades genéricas originadas no ambiente acadêmico, essas habilidades indicam capacidades informacionais nas variadas práticas sociais, em contínuo desenvolvimento ao longo da vida. O foco nas habilidades em processos de busca de informação - geralmente ligadas à forma (suporte) da informação - dão espaço para uma variável até então pouco explorada (certamente, por reflexo na formação generalista dos bibliotecários, principal instrutor do processo anterior): o uso efetivo da informação. Influenciar efetivamente no uso do conteúdo dos documentos exige uma nova configuração da educação bibliotecária, orientada pelo trabalho colaborativo dos atores multiplicadores das competências em informação (não apenas bibliotecários) 
Tanto na escola quanto na universidade, o papel da biblioteca à luz da noção de competências em informação vai além da capacitação na busca e uso das fontes. Nesta nova modalidade de capacitação, Belluzzo (2008) destaca a noção de aprendizagem ao longo da vida e o trabalho colaborativo entre bibliotecários e professores. Dentre as ações a serem estimuladas, destaca-se:

- Preparação de diretrizes básicas para iniciativas conjuntas sob o enfoque das necessidades da sociedade da informação e dos princípios da Competência em Informação, uma atividade intracurricular.

- Definir as condições para que tais iniciativas possam ser apoiadas por políticas e pelas comunidades assistidas.

- Implementar e criar mecanismos de manutenção e avaliação das práticas pedagógicas e informacionais. (BELUZZO, 2008, p. 13).

Corroborando, Cuenca, Noronha e Alvarez (2008, p. 48) pontuam que

[...] as bibliotecas nos dias atuais, devem ser vistas também como centros de aprendizado, com sua equipe desempenhando - papel fundamental educativo, oferecendo cursos e treinamentos para que os usuários conheçam os sistemas de recuperação da informação, arquitetura das bases de dados e a organização da informação nas diferentes áreas do conhecimento.

As práticas de competências em informação nas bibliotecas escolares, segundo Campello (2009), ainda continua deficiente. Apesar do papel estratégico no desenvolvimento da criança e do adolescente, a biblioteca escolar não "saiu do papel". Estão longe, por exemplo, do padrão proposto por bibliotecários estadunidenses da California School Library Association (CSLA):

a) Jardim da infância (Kindergarten): identificar tipos de materiais digitais e impressos diariamente; entender a necessidade de pedir permissão a um adulto de confiança quando solicitado a fornecer informações, pessoalmente em um formulário ou online;

b) Série 1: demonstrar o procedimento correto para ligar e desligar um computador, e para abrir e fechar aplicativos; entender que a internet é o modo como o computador se conecta com o resto do mundo;

c) Série 2: usar elementos gráficos de softwares de computador e ferramentas de navegação (botões, ícones, etc.);

d) Série 3: definir cyberbullying e seus efeitos; selecionar ferramentas e fontes de tecnologias de informação apropriadas para interagir com os outros;

e) Série 4: criar documentos simples, usando mídias eletrônicas

e empregando recursos de organização (senhas, menus de 
entrada e pull-down, termos de pesquisa, tesauros e verificação ortográfica); comunicar-se com outros fora do ambiente escolar, através do uso de tecnologia (vídeo conferência, blog, wiki, chat, fóruns de discussão);

f) Série 5: comparar e contrastar informação obtida por bases de dados restritas (assinadas), das disponibilizadas pelos motores de pesquisa abertos na internet; usar os procedimentos básicos de segurança ao utilizar e-mail ou outra atividade na internet;

g) Série 6: colaborar pessoalmente e através da tecnologia na identificação de problemas e busca de soluções; identificar programas que podem danificar o computador (vírus, worms, trojans, spyware);

h) Séries 7 e 8: entender e comunicar o uso ético da propriedade intelectual; usar uma variedade de mídias (som, imagem, escrita) para transmitir informações, compartilhar opiniões e convencer um público; i) Série 9 a 12: usar uma variedade de motores de pesquisa e base de dados especializada para localizar informação relevante; possuir comportamentos apropriados e uma boa cidadania online (FARMER, 2010 apud SERAFIM; FREIRE, 2013, p. 82).

O perfil deficitário em competências em informação na idade escolar dificulta a inserção do estudante brasileiro no regime de informação acadêmico, o qual é caracterizado, segundo Bernhard (2002), pelos seguintes fatores:

a) Crescimento exponencial da informação disponível e acessível em qualquer formato;

b) A informação é cada vez mais heterogênea, cuja autenticidade, validez e credibilidade têm de ser estabelecidas continuamente;

c) Contexto econômico baseado fortemente em atividades de serviços e tecnologias em rápido desenvolvimento;

d) A necessidade de que cada pessoa adquira e desenvolva aptidões transferíveis e utilizáveis ao longo da vida, assim como a de aprender a aprender visando solucionar problemas;

e) A necessidade absoluta de estar a par dos desenvolvimentos mais recentes para as atividades de investigação;

f) A demanda dos empregadores que querem contratar as pessoas capazes de dominar as tecnologias, de buscar a informação em fontes eletrônicas e na Internet e de avaliá-la, de negociar a informação interna e externa, assim como de realizar as atividades de alerta;

g) A evolução para uma pedagogia ativa centrada no estudante, 
baseada nos recursos e na solução de problemas;

h) O impacto da formação no uso da informação sobre a continuidade nos estudos e no êxito escolar.

\section{METODOLOGIA}

Com o intuito de descrever práticas de informação à luz das competências em informação dos o esforço de compreender o fenômeno das competências em informação dos usuários da Biblioteca da Universidade Estadual da Paraíba (SIB/UEPB), Campus IV, Catolé do Rocha - Paraíba e criar instrumento válido (útil), com possibilidade de ser aplicado na contextura local, realizou-se pesquisa participante, definida por Minayo (2009, p. 70) como "[...] um processo pelo qual um pesquisador se coloca como observador de uma situação social, com a finalidade de realizar uma investigação científica". O campo do estudo é o local em que o pesquisador exerce suas funções como bibliotecário desde outubro de 2012 até os dias atuais.

Nesta investigação sobre a experiência de informação dos usuários reais desta biblioteca, segmentou-se o estudo das dimensões informacionais das práticas dos alunos (dos variados níveis escolares e acadêmicos). Seguindo tendência de estudos de práticas de informação orientados por visão de informação qualitativa e holística, faz-se uso de um mix de métodos de coleta de dados. Para Mason (2006 apud BAGNOLI, 2009, p. 248), o uso de combinação de métodos de pesquisa (Mixed Methods Research) "[...] pode encorajar 0 pensamento 'fora da caixa', gerando novos meios de interrogar e compreender o social".

Esses procedimentos foram utilizados de modo combinado em Tour Guiado (HARTEL, 2007; SERAFIM, 2016) - momentos em que os pesquisados são convidados a guiarem o pesquisador em espaços de informação (bibliotecas, por exemplo), descrevendo suas práticas. Em estudos de competências em informação, é sempre oportuno separar dados de percepção e dados de desempenho, reforçando-se que os dados de percepção são insuficientes para avaliar competências em informação: "[...] questões como 'Você considera úteis 
as técnicas de pesquisa ensinadas pelos bibliotecários?' não possibilita avaliar se a pessoa sabe ou não aplicar essas técnicas" (ABDULLAH, 2010 apud SERAFIM; FREIRE, 2016).

Nesses encontros, foram utilizados, de modo acordado através de Termos de Consentimento, entrevistas semiestruturadas e equipamentos de áudio e imagem (fotografias). Os dados coletados foram estruturados e analisados de acordo com método qualitativo de interpretação dos sentidos (MINAYO, 2009, p. 75), o qual propõe:

a) Leitura compreensiva do material selecionado - nesta etapa, constróise uma estrutura básica para interpretação, sendo realizada constantemente uma categorização dos dados coletados;

b) Exploração do material - a análise densa das falas, dos gestos, dos fatos observados segue a seguinte trajetória;

c) Elaboração de síntese interpretativa - ocorre a interpretação propriamente dita, na qual os dados coletados são decompostos em unidades; articulam-se os objetivos do estudo, a base teórica adotada e os dados empíricos.

\section{RESULTADOS}

A realidade informacional dos estudantes assistidos pela biblioteca integrante do Sistema de Bibliotecas da UEPB, em Catolé do Rocha, Estado da Paraíba, é bastante singular. Trata-se de uma biblioteca multinível - aquela orientada por público de variados níveis de processos formativos (ensino médio, técnico e superior) (ALMEIDA; FREIRE, 2018) - localizada na zona interiorana o Estado da Paraíba, da cidade de Catolé do Rocha.

Durante a primeira fase da pesquisa, ocorreu um período de greve das atividades acadêmicas, fato que alterou a dinâmica de coleta de dados, os quais foram coletados 3 momentos distintos:

a) Coleta de dados demográficos e de percepção sobre fontes, atendimento oferecido pela biblioteca, conveniência em busca de informação; 
b) Encontros individuais com os pesquisados e a realização de Tours Guiados: coleta de dados de desempenho mediante a realização de atividade de busca de informação no espaço da biblioteca;

c) A realização de treinamento com base nas dificuldades apresentadas no momento anterior.

Dos 27 participantes, a maior parte (91\%) são jovens na faixa etária entre 11 a 30 anos, oriundos tanto dos cursos de nível superior, quanto dos cursos de Ensino Médio/Técnico (Gráfico 1).

\section{Gráfico 1 - Escolaridade}

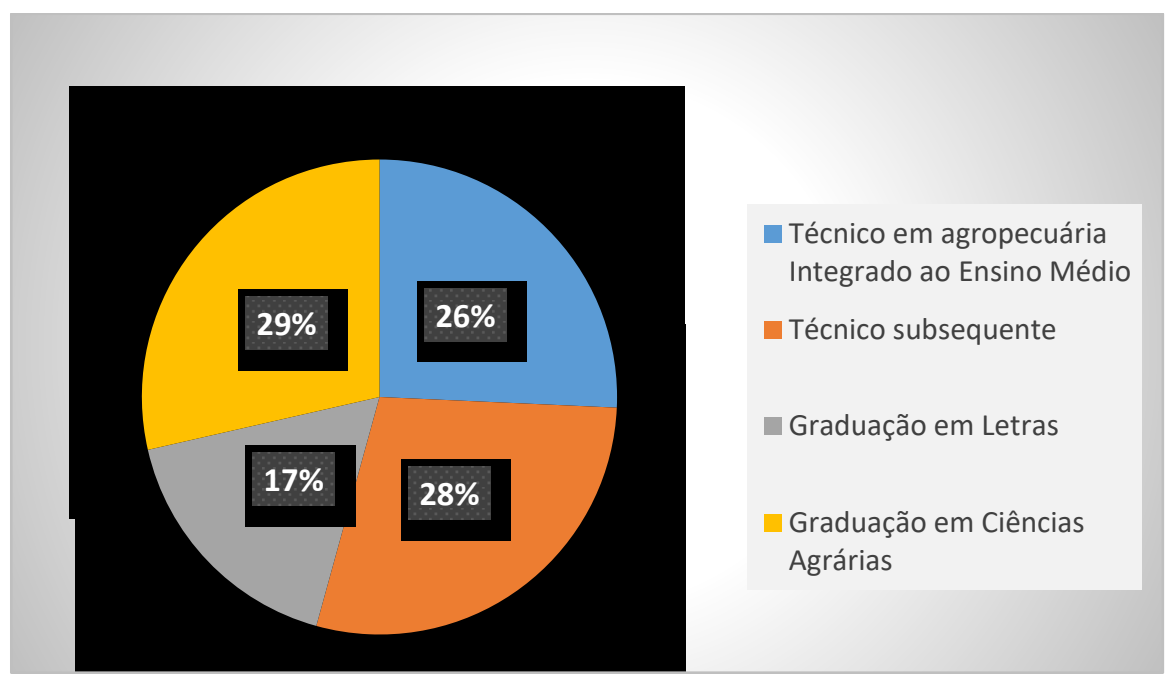

Fonte: Dados da pesquisa.

Em reflexo à contemporaneidade marcada pelo uso massivo das novas Tecnologias de Informação e Comunicação, principalmente pela população mais jovem, constatou-se a preferência majoritária pelo uso dos motores públicos de pesquisa - um fenômeno recorrente em estudos de práticas de informação da sociedade atual (Gráfico 2). 


\section{Gráfico 2 - Onde se busca acesso à informação científica}

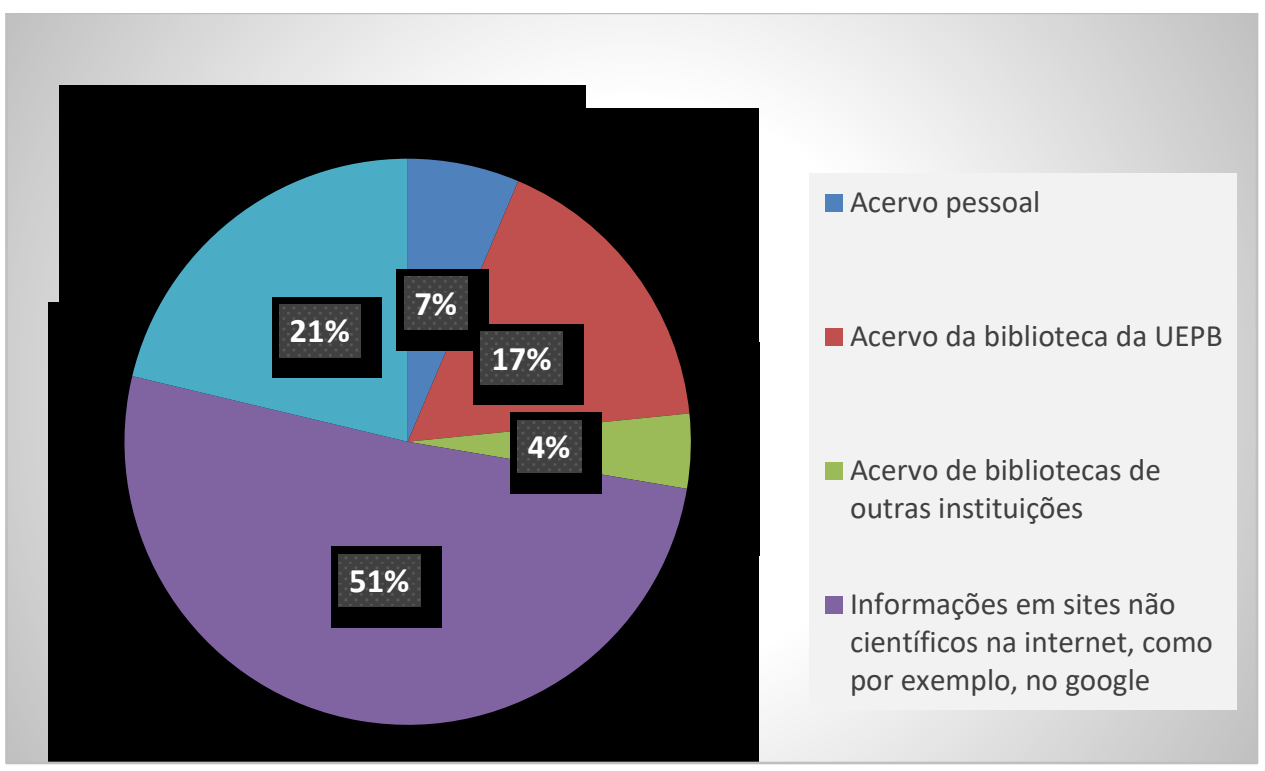

Fonte: Dados da pesquisa.

A capacitação para lidar com os ambientes digitais, com desejável postura crítica e cética com conteúdos não formais, não confiáveis, não seguros, marcados pela desinformação (popularmente referenciada como fake news), informação errônea (errada de forma acidental), ou mesmo grande volume de dados, não é reforçada pela biblioteca sob estudo - instituição pioneira nesta tarefa (FALLIS, 2015). Enquanto $71 \%$ dos pesquisados afirmam que a biblioteca não promove ação educacional em informação, outros $29 \%$ não sabem informar sobre o assunto.

A biblioteca pesquisada, apesar da falha em instruir seus usuários em relação ao seu uso (e no uso de informação), é uma importante aliada nas atividades de ensino aprendizagem do grupo estudado. Diferentemente da grande parte das bibliotecas multiníveis ou universitárias dos grandes centros, bem equipadas tanto em infraestrutura física, quanto em recursos humanos e tecnológicos - garantidos principalmente por reconhecido aparato teórico e legal - a realidade da Unidade de Catolé do Rocha é marcada pela simplicidade (Figura 1). 
Figura 1 - Espaços da Biblioteca

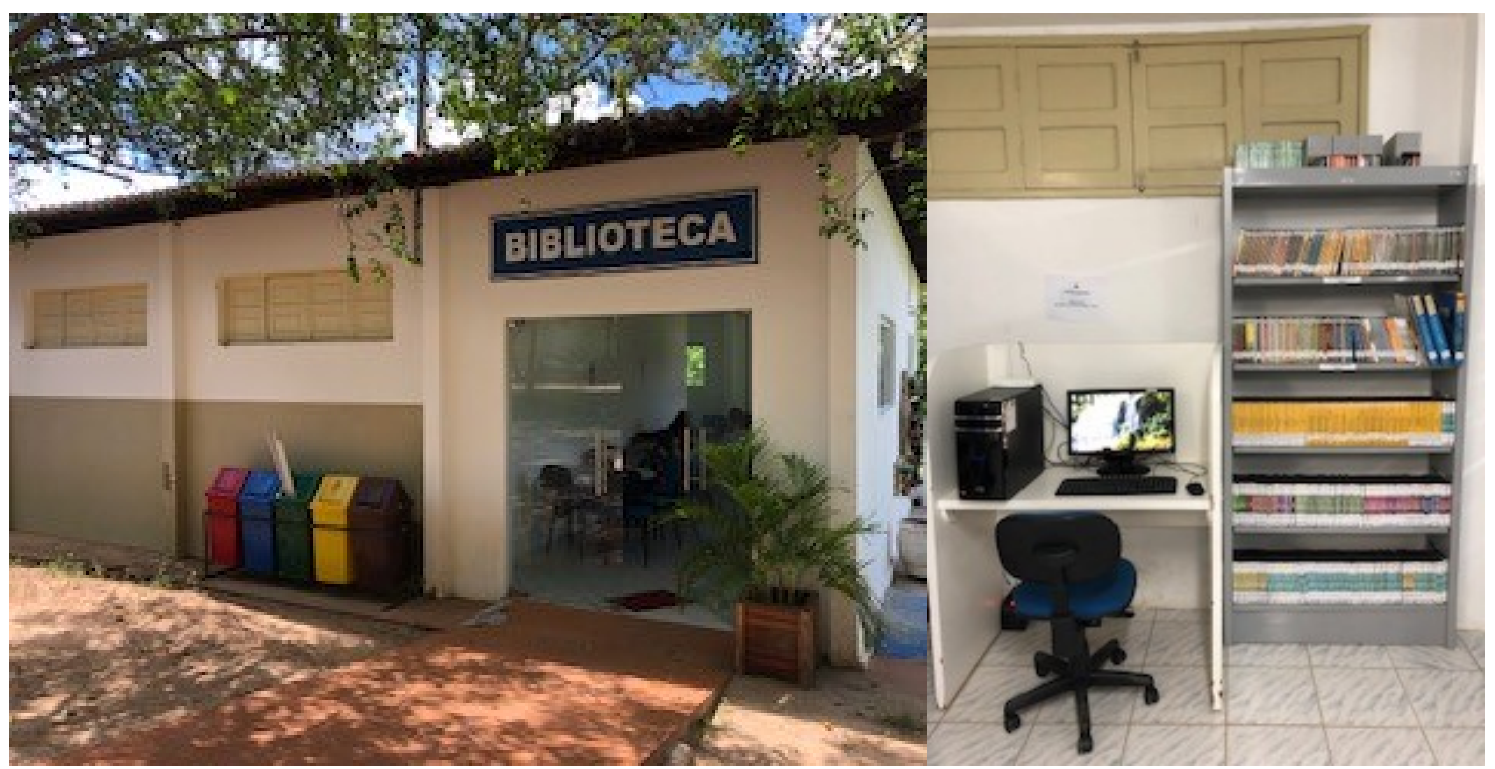

Fonte: Dados da pesquisa.

Nota: Entrada da biblioteca; único computador para consulta ao acervo (local e online) e pesquisas bibliográficas na internet.

A falta de modernização do espaço não diminui o alto nível de satisfação dos usuários com os serviços prestados pela biblioteca: $83 \%$. Os motivos são variados, destacando-se, nesta realidade, o espaço de estudo, o atendimento, as fontes e o acesso à internet (apesar de problemático e restrito, conforme Figura 1): "Bem, confortável. Estudar avaliações da instituição, pesquisas sobre determinados assuntos em livros e com uso da internet" (Pesquisado 23).

No segundo momento da pesquisa, convidou-se os pesquisados para os encontros individuais, nos quais foram solicitados Tours Guiados sobre práticas de busca de informação. Certamente, este é o momento de pesquisa mais valorizado pelos estudiosos de competências em informação. Participaram dos encontros, sobretudo pelo fator greve, apenas 5 pesquisados. A relevância dos dados coletados, todavia, não foi afetada.

Nas variadas narrativas, destacou-se um ponto em comum: a importância de se ter habilidades de busca de informação. Quando não aprendidas e praticadas, são supridas pelo auxílio dos recursos humanos da biblioteca, como observa-se no Quadro 1. 


\section{Quadro 1 - Como você procede a busca de informação na biblioteca?}

\begin{tabular}{|c|l|}
\hline Participantes & \multicolumn{1}{c|}{ Respostas } \\
\hline 1 & $\begin{array}{l}\text { "O usuário quer encontrar na biblioteca são os livros, pesquisas na internet, } \\
\text { ajuda dos auxiliares e dos bibliotecários para tirar suas dúvidas". }\end{array}$ \\
\hline 2 & $\begin{array}{l}\text { "Sempre peço ajuda de um funcionário para fazer minhas pesquisas por } \\
\text { informação, tenho muita dificuldade de encontrar sozinho". } \\
\text { "Identifico a temática do que estou pesquisando e olho nas prateleiras por } \\
\text { etapas, buscando um livro com o conteúdo mais próximo que eu queira". }\end{array}$ \\
\hline 3 & $\begin{array}{l}\text { "Quando chego na biblioteca vou direto pra o acervo buscar minha } \\
\text { informação". }\end{array}$ \\
\hline 5 & $\begin{array}{l}\text { "Eu raramente vou a biblioteca, não sei procurar informação nesse } \\
\text { espaço tão grande, tenho dificuldade demais". } \\
\text { "Quando eu vou procuro livros, monografias e na internet, porém se } \\
\text { ninguém me ajudar, não encontro a informação". }\end{array}$ \\
\hline
\end{tabular}

Fonte: Dados da pesquisa (grifo nosso).

As barreiras em processos de busca e uso de informação ficaram mais evidentes, explicitadas das afirmações abstratas do primeiro momento da pesquisa (dados de percepção).

\section{Quadro 2 - Quais suas dificuldades na busca da informação?}

\begin{tabular}{|c|l|}
\hline Participantes & \multicolumn{1}{c|}{ Respostas } \\
\hline 1 & $\begin{array}{l}\text { "Geralmente não tem internet para realizar a pesquisa ou no acervo não } \\
\text { tem o livro, muitas vezes são poucos e estão emprestados". }\end{array}$ \\
\hline 2 & $\begin{array}{l}\text { "Como já falei, tenho muitas dificuldades de encontrar informação na } \\
\text { biblioteca, falta muito algum tipo de ajuda por parte do pessoal da } \\
\text { biblioteca". }\end{array}$ \\
\hline 3 & "O acesso à internet é de má qualidade". \\
\hline 4 & $\begin{array}{l}\text { "Tenho dificuldades de usar o catálogo da biblioteca e de encontrar como } \\
\text { usar as normas nos trabalhos que os professores sempre pedem nas } \\
\text { normas da ABNT". }\end{array}$ \\
\hline 5 & $\begin{array}{l}\text { "Tenho dificuldades de encontrar e usar as normas da ABNT. Estou } \\
\text { terminando minha graduação e até agora não sei usar essas normas que os } \\
\text { professores pedem mais ninguém ensina como usá-las". }\end{array}$ \\
\hline
\end{tabular}

No terceiro momento da pesquisa, apresentou-se um breve treinamento, cujo conteúdo orientou a estruturação de proposta de uma política formal de educação em competências em informação, a ser analisada e, possivelmente, implementada pela biblioteca da UEPB em Catolé do Rocha. Trata-se da Política de Desenvolvimento de Competências em Informação: Proposição de Cursos, pautada em dois cursos:

a) A biblioteca e suas múltiplas formas de encontrar a informação que preciso;

b) Como faço meus trabalhos acadêmicos? Quem pode me ajudar?

A presente pesquisa iniciou as suas ações investigativas tendo como mola 
mestra a necessidade urgente das pessoas da contemporaneidade em serem competentes em informação. Mediante o vasto corpo teórico sobre o tema, compreende-se que, nos contextos biblioteconômicos, as habilidades de uso dos recursos da biblioteca - tradicionalmente desenvolvidas em ações de educação de usuários - são insuficientes para o alcance de posturas mais críticas em relação às informações que tecem outros setores da vida humana.

$\mathrm{Na}$ prática, todavia, observa-se em mais uma realidade de biblioteca brasileira - multinível e localizada na zona interiorana do nordeste brasileiro - o longo caminho a ser seguido na busca de capacitação de usuários de informação. Neste caso em particular, o anseio pelo desenvolvimento de competências em informação depara-se com o fato de que falta habilidades mais básicas sobre o uso da biblioteca, motivo pelo qual se defende que as primeiras ações sejam sobre o uso da biblioteca.

Assim, os cursos propostos, por mais elementares que possam parecer à luz da moderna noção de competências em informação, são o ponta pé inicial para o fomento de novas ações para além do âmbito biblioteconômico e institucional, que promovam a integração curricular, capacitação de multiplicadores de competências em informação, trabalhos colaborativos com docentes e promoção de boas práticas a serem exercitadas ao longo da vida.

\section{CONCLUSÃO}

A necessidade de capacitar a comunidade acadêmica da biblioteca da UEPB de Catolé do Rocha é, há algum tempo, percebida na prática cotidiana da biblioteca, na qual os usuários frequentemente demonstravam dificuldades na realização de buscas de informação. A realização desta pesquisa oportunizou o aprofundamento e sistematização do cenário biblioteconômico local e, consequentemente a proposição de uma política formal que visa sugerir melhorias em torno de treinamento dos usuários com base em situaçõesproblemas reais decorrentes da vida escolar e acadêmica, de modo a torná-los competentes em informação.

Além da relevância para os usuários, este documento/política contribui 
para a mudança da tendência problemática das Organizações bibliotecárias em geral, nas quais as necessidades e práticas de informação dos seus usuários não são suficientemente conhecidas, contribuindo para a subutilização desses sistemas. Trata-se de um produto baseado em estudo com dados reais, os quais ressaltam a demanda por capacitações em processos de busca e uso de informação. Por mais básico e essencial que esta postura administrativa possa parecer, é inédita em âmbito local, já que, assim como em muitas realidades biblioteconômicas brasileiras, é inexistente.

\section{REFERÊNCIAS}

ALMEIDA, Jobson Louis Santos de; FREIRE, Gustavo Henrique de Araújo. A Biblioteca Multinível no IFPB Campus Sousa: conceito, descrição e finalidade. Informação \& Informação, Londrina, v. 23, n. 2, p. 520-537, maio/ago. 2018.

\section{ALMEIDA, Maria Christina Barbisa de. Planejamento de bibliotecas e serviços de informação. Brasília: Briquet de Lemos, 2005.}

ANDRADE, Marcos Vinícius Mendonça. Gestão da qualidade em bibliotecas universitárias: indicadores de desempenho e padrões de qualidade. 2004. Dissertação (Mestrado em Engenharia de Produção) - Universidade Federal Fluminense, Programa de Pós-Graduação em Engenharia de Produção, Niterói, 2004.

BAGNOLI, Anna. Beyond the standard interview: the use of graphic elicitation and arts-based methods. Qualitative Research, v. 9, n. 5, p. 547-570, 2009.

BELLUZZO, Regina Célia Baptista. Como desenvolver a Competência em Informação $(\mathrm{Cl})$ : uma mediação integrada entre a biblioteca e a escola. CRB-8 Digital, São Paulo, v. 1, n. 2, p. 11-14, out. 2008.

BERNHARD, Paulette. La formación en el uso de la información, una ventaja en la enseñanza superior, situación actual. Anales de Documentación, Murcia, Espanha, n. 5, 2002.

CAMPELLO, Bernadete Santos. Letramento informacional: função educativa na escola. Belo Horizonte: Autêntica, 2009.

CAMPELLO, Bernadete; ABREU, Vera Lúcia Furst Gonçalves. Competência informacional e formação de bibliotecário. Perspectivas em Ciência da informação, Belo Horizonte, v. 10, n. 2, p. 178-193, jul./dez. 2005.

CUENCA, Ângela Maria Belloni; NORONHA, Daisy Pires; ALVAREZ, Maria do Carmo Avamilano. Avaliação da capacitação de usuários para a recuperação 
da informação: o caso de uma biblioteca. Revista Brasileira de

Biblioteconomia e Documentação, São Paulo, v. 4, n. 1, p. 46-58, jan./jun. 2008.

DUDZIAK, Elisabeth Adriana. A information literacy e o papel educacional das bibliotecas. 2001. 173 f. Dissertação (Mestrado em Ciências da Comunicação) - Escola de Comunicação e Artes, Universidade de São Paulo, 2001.

FALLIS, Don T. What is disinformation? Library Trends, Arizona, v. 63, n. 3, 2015.

FEDERAÇÃO BRASILEIRA DAS ASSOCIAÇÕES DE BIBLIOTECÁRIOS. Declaração de Maceió sobre a competência em informação. 2011.

Disponível em: http://febab.org.br/declaracao_maceio.pdf. Acesso em: 23 mar. 2018.

HARTEL, Jenna. Information activities, resources, and spaces in the hobby of Gourmet Cooking. 2007. Published Doctoral Dissertation - University of California, Los Angeles, 2007.

ISLAM, Shariful; ISLAM, Nazmul. Marketing of library and information products and services: a theoretical analysis. Business Information Review, v. 26, n. 2, p. 123-132, 2009.

MILANESI, Luís. O que é biblioteca. São Paulo: Brasiliense, 1983.

MINAYO, Maria Cecília de Souza (org.). Pesquisa social: teoria, método e criatividade. Petrópolis: Vozes, 2009.

ROWLEY, J; ROBERTS, S. The reluctant leader?: leadership and the information profession. Library and information update, [s. I.], v. 7, n. 7/8, p. $52-54,2008$.

SERAFIM, Lucas Almeida. Competências em informação e The Serious Leisure Perspective: um novo espaço de interlocução. 213 f. 2016. Tese (Doutorado em Ciência da Informação) - Universidade Federal da Paraíba, João Pessoa, 2016.

SERAFIM, Lucas Almeida; FREIRE, Gustavo Henrique de Araújo.

Competências em informação na contemporaneidade. RACIn, João Pessoa, v. 1, n. 1, p. 67-87, jan./jun. 2013.

SERAFIM, Lucas Almeida; FREIRE, Gustavo Henrique. Ação de responsabilidade social para competências em informação. Perspectivas em Ciências da Informação, v. 17, n. 3, p. 155-173, jul./set., 2012. 
SERAFIM, Lucas Almeida; FREIRE, Gustavo Henrique. Incompetências em informação: o caso da conveniência na busca por informação. Em Questão, Porto Alegre, v. 22, n. 2, p. 36-59, mai/ago. 2016

SOCIETY OF COLLEGE, NATIONAL AND UNIVERSITY LIBRARIES. The SCONUL Seven Pillars of Information Literacy: core model for higher education. London: SCONUL, 2011. Disponível em: https://www.sconul.ac.uk/sites/default/files/documents/coremodel.pdf. Acesso em: 08 abril 2019.

\title{
ZURKOWSKI, Paul G. The Information Service Environment Relationships
} and Priorities: related paper $n^{\circ} 5$. Washington: National Commission on Libraries and Information Science, 1974.

\section{INFORMATION LITERACY IN A MULTILEVEL LIBRARY OF INTERIOR REGION OF THE STATE OF PARAIIBA, PB, BRAZIL}

\begin{abstract}
Introduction: Information literacy is a recurring subject in the literature on Library and Information Science, whether in theoretical approaches on the contemporary informational phenomenon or in empirical reports about information search and use in Information Units. In the level of implementation, the promotion of information literacy occurs in formalized, institutionalized educational programs, which reinforce and broaden the traditional user library education. In reality, however, that does not occur at the major Brazilian information environment, especially at the school and academic multilevel ones, which are scrutinized in this research. Objective: It analyzes the scenario of practices oriented by information literacy in Brazilian multilevel library. Methodology: the study performs participant research, based on a set of methods for the description of information practices, namely "guided tour" in information environments, semi-structured interview, visual research, and the qualitative method of interpretation of meanings. Results: It finds - in one more reality of multilevel Brazilian library and located in the rural area of northeastern Brazil - a long way to be followed by this library to reach information literacy; the most basic skills about library use are missing in the most of participants. In order to change this reality, the study proposes a formal policy for information literacy development, initially based on the indication of courses. Conclusions: This research offered data for a deeper understanding about the local context of the library and, consequently, to propose a policy that aims to suggest improvements through information literacy education based on real-situation problems arising from school and academic life, in order to make them information competent.
\end{abstract}

Descriptors: Information literacy. Library users' education. Multilevel library. Academic library. School library.

\section{ALFABETIZACIÓN INFORMATIVA EN BIBLIOTECA MULTINIBLE DE REGIÓN INTERIORANA DEL ESTADO}




\title{
DE LA PARAÍBA, PB, BRASIL
}

\begin{abstract}
RESUMEN
Introducción: La alfabetización informativa (information literacy) son asunto recurrente en la literatura de Biblioteconomía y Ciencia de la Información, sea en abordajes teóricos sobre el fenómeno informativo en la contemporaneidad, sea en relatos empíricos acerca de la búsqueda y uso de la información en Unidades de Información. En el ámbito de implementación, la promoción da alfabetización informativa ocurre en acciones educativas formalizadas, institucionalizadas, que refuerzan y amplían la tradicional educación de usuarios de bibliotecas. Esta realidad, sin embargo, aún no caracteriza la mayor parte del ambiente informativo brasileño, principalmente el escolar y académico - multinivel, escrutado en esta investigación. Objetivo: Analiza el escenario de prácticas orientadas por alfabetización informativa en biblioteca multinivel brasileña. Metodología: Realiza investigación participante, basada en un conjunto de métodos para la descripción de prácticas de información, a saber: "tour guiado" en ambientes de información, entrevista semiestructurada, investigación visual, y método de interpretación de sentidos. Resultados: Constata - en otra realidad de biblioteca brasileña multinivel y ubicada en la zona rural del nordeste brasileño - un largo camino a seguir por la biblioteca bajo estudio en la búsqueda de alfabetización informativa; se carece de fomento de las habilidades más básicas sobre el uso de la biblioteca. Para suplirlas, propone una política formal de alfabetización informativa, basada inicialmente en la indicación de cursos. Conclusiones: La realización de esta investigación oportunas la profundización y sistematización del contexto bibliotecológico local y, consecuentemente, la proposición de política que busca sugerir mejoras por medio de entrenamiento de los usuarios con base en situaciones-problemas reales derivados de la vida escolar y académica, de modo que hacerlos competentes en información.
\end{abstract}

Descriptores: Alfabetización Informativa. Educación de Usuarios. Biblioteca Multinivel. Biblioteca Académica. Biblioteca Escolar.

Recebido em: 07.07.2019

Aceito em: 09.09.2019 